\title{
Maximizing E-Tailers' Sales Volume through the Shipping-Fee Discount and Product Recommendation System
}

\author{
Yan Guo, ${ }^{1,2}$ Xiaonan Hu, ${ }^{1}$ Yu Zou, ${ }^{1}$ Shouwei Li, ${ }^{3}$ Wenchuan Cheng, ${ }^{1}$ and Zhiyong Li $\mathbb{D}^{1,2}$ \\ ${ }^{1}$ College of Information Engineering, Sichuan Agricultural University, Yaan, Sichuan, China \\ ${ }^{2}$ Key Laboratory of Agricultural Information Engineering of Sichuan Province, Sichuan Agricultural University, Yaan, \\ Sichuan, China \\ ${ }^{3}$ Department of Admission and Employment Office, Chengdu Agricultural College, Chengdu, Sichuan, China
}

Correspondence should be addressed to Zhiyong Li; lzy@sicau.edu.cn

Received 20 October 2019; Revised 14 January 2020; Accepted 21 February 2020; Published 26 March 2020

Academic Editor: Manuel De la Sen

Copyright (C) 2020 Yan Guo et al. This is an open access article distributed under the Creative Commons Attribution License, which permits unrestricted use, distribution, and reproduction in any medium, provided the original work is properly cited.

\begin{abstract}
E-tailers can impact customers' order incidence and cart size by offering an attractive shipping fee; they can also influence customers to purchase other products using a recommendation system. This article provides a combined model in which the shipping-fee discount and product recommendations occur jointly to maximize the sales volume of e-tailers. Selection of recommended products and discount of shipping fee are the dynamic issues involving the complexity of business environments. The proposed model first determines the optimal shipping-fee discount to attract customers and then establishes the most suitable product recommendation list to encourage customers to spend more money on other products. Through the use of a shipping-fee discount and simultaneous product recommendations, e-tailers maximize the sales volume. As for consumers, they can always get additional savings from the subsequent shopping process because the product's shipping fee is lower than the original shipping costs. Experimental results indicate that the proposed approach is feasible and better than alternative methods for achieving sales volume maximization. Furthermore, sensitivity analysis validates the stability of the proposed model in the face of an uncertain environment. Therefore, using the shipping-fee discount and product recommendation system as a united marketing strategy can maximize e-tailers' sales volume.
\end{abstract}

\section{Introduction}

An explosion of e-business has occurred over the last decade [1]. In 2019, retail e-commerce sales will expand $27.3 \%$, reaching $\$ 1.935$ trillion, or $36.6 \%$ of total retail sales. EMarketer forecast that retail e-commerce sales will maintain strong growth by the end of 2023 [2].

E-commerce has greatly improved the efficiency and efficiency of traditional business activities. From the view of consumers, online shopping has the advantage of making it easy to purchase items and compare prices. Online sales reduce intermediate links, reduce transaction costs, redefine the traditional circulation model, and enable direct transactions between producers and consumers. Companies can transfer savings to consumers, which is why the well-known online bookstore Amazon can offer consumers discounts that traditional bookstores cannot provide. At the same time, online shopping is not restricted by store location and business hours. Traditional commerce is shop-style sales characterized by fixed sales locations (i.e., stores) and fixed sales hours. Online sales are carried out through online stores featuring information databases, so its sales space extends with the extension of the network system. There are no geographical barriers, and its retail time is determined by consumers, namely, online users.

However, the disadvantage of online shopping is the price impact when the freight increases the total cost of the purchase. For example, Dasiy wants to buy a household mop and the online price is 7 percent lower than the brick-andmortar price before considering the shipping fee. However, adding those charges results in a 10 percent increase in the total purchase price, which causes her to cancel the online 
purchase. Expensive shipping costs disappoint and frustrate many customers. A survey by PayPal found that a high transportation cost is the main reason customers abandon the shopping cart without making a purchase. Approximately half of the online shoppers abandon their carts due to the increase in shipping costs [3]. Expensive shipping fees prevent customers from completing online transactions, which leads to a loss of sales for e-tailers [4].

Because of the role of transport costs in determining profitability, e-tailers have introduced various measures to mitigate the negative impacts [5]. Promotions such as free shipping on specific orders are also applied to lessen the impact of shipping costs [6]. Lewis et al. [7] contend that free shipping and value-contingent free shipping are effective methods to attract consumers. ComScore [8] found that $42 \%$ of online shoppers in Asia added items to their shopping carts in order to qualify for free shipping. So more and more e-commerce platforms have used free shipping to attract online consumers' shopping in order to improve the platforms' performance $[9,10]$.

While discounted shipping fees can attract and convert customers effectively, they create a real dilemma: the collection of transportation costs to compensate for the cost of the e-tailer's transportation often dissuades the customers from purchasing, while reducing the cost of transportation leads to a loss in the e-tailer's profits [5].

In addition to the use of discounts on shipping fees to retain consumers, e-tailers can offer more value-added services to customers through the use of information technology. For example, online recommendations reduce the consumers' web search costs and provide valuable product information $[11,12]$. Because of the strong complementarity and substitution in the products $[13,14]$, e-tailers can take advantage of the interaction of product recommendation and complementarity and substitution effects to discover the products that best suit the customer. As mentioned above, we could recommend to Dasiy a mop head for the household mop whose purchase price is equivalent to the shipping fee without the freight. Dasiy could buy all the products, which increases the amount purchased.

How to combine the freight discount with the recommendation system to make consumers buy products instead of giving up the purchase behavior, so as to ultimately maximize sales volume for e-tailers? It is generally accepted that recommendations change the customer's value of the product $[15,16]$. We assume that the e-tailer's recommendation strengthens the product value and put forward a combined model to maximize the impact of product recommendations. This model enables an e-tailer to use freight discounts to attract customer traffic and compensates for the loss of profits caused by the shipping-fee discount by enhancing the sales volume of other recommended products; this article mainly focuses on the following three issues:

(1) How is the shipping-fee discount rate set, and how are products selected to recommend, considering that customers can buy any product and that the customers' valuation of the product is affected by the recommendation? Figure 1 shows an example of the shipping fee and the product recommendation on Taobao.com. In Figure 1, the mop on the largest picture in the upper left corner is the product consumers want to buy initially. The text on the right describes the price, freight, payment method, and other information of the product. At the bottom is the recommendation of other related products. The portion highlighted by the red box is the main focus of our study: how to decide the shipping-fee discount, and how to select the products to recommend.

(2) What is the influence of the product recommendation on the shipping-fee discount, and the sales volume under the shipping-fee discount?

(3) How do changes in the reservation price, the recommendation accuracy, and the complementary products influence the retailer's sales volume?

To obtain more sales volume, online retailers should take advantage of the relationship between shipping-fee schedules and recommendations. This paper provides a valuable model for managers to optimize the use of online functions to serve customers and improve the sales volume of e-tailers. E-tailers can acquire the largest sales volume through the systematic consideration of the relationship between the shipping-fee discounts and product recommendations. Using Taobao.com data, we utilize product features to provide guidance on the online shipping-fee discount and product recommendations.

The rest of this research is organized as follows. Section 2 reviews the literature on shipping-fee research and recommendation systems. Section 3 presents a model to optimize an e-tailer's sales volume through the shipping-fee discount and product recommendations. In Section 4, a case study is used to illustrate the performance of the proposed model. Sensitivity analysis of the proposed model is given in Section 5. Lastly, the conclusions and discussion are provided in Section 6.

\section{Literature Review}

2.1. Shipping Strategy. Current studies on shipping strategy emphasize the shipment policies of manufacturers in the offline environment [17]. The literature on online retailer's shipping-fee strategies is mainly composed of two streams. Some researchers believe that sales prices and transportation costs should be considered separately and consider the selling price as the base and the shipping fees as surcharges $[18,19]$. Morwitz et al. [20] show that the partitioned strategy increases the customers' demand for products. Regarding the impacts of the shipping fee on purchase intention, Lewis et al. [7] find that customers are more sensitive to shipping fees than to product prices and that the sensitivity to shipping charges has a direct effect on the customers' purchase intentions. Burman and Biswas [21] show that for customers with a high need for cognition, a partitioned strategy has a significantly favorable effect on customers' purchases when surcharges are reasonable and the effects reverse when surcharges are unreasonable. 


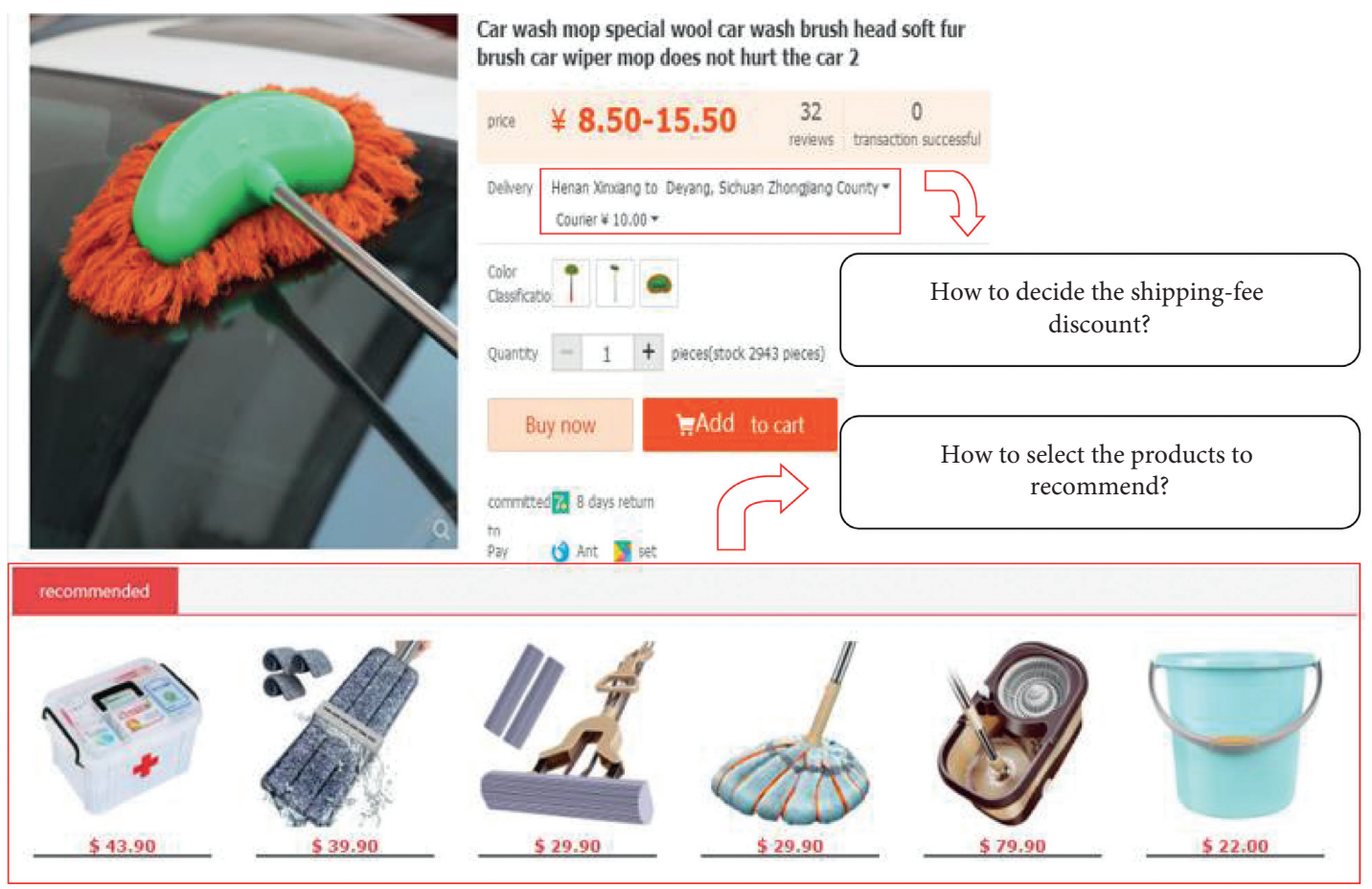

FIgURE 1: An example of the shipping fee and recommendation on Taobao.com.

However, due to the different characteristics of electronic retailers and customers, it is not applicable to all situations. Cheema [22] maintains that charging a shipping fee separately has a negative impact on reputation and on e-tailers' sales. To guide the e-tailers to choose the best solution, Gümüs et al. [23] propose a stylized game-theoretic model to capture the competitive dynamics between the partitioned and combined strategies. Based on the dual entitlement principle, Huang et al. [4] developed a conceptual model to examine the possible influence on the relationship among threshold level, freight, and delivery time.

Most studies in the second stream focus on the effects of transportation on the customers' purchase decisions and loyalty [24, 25]. Lewis et al. [7] contend that free shipping and value-contingent free shipping are effective methods to attract consumers. Hua et al. [26] examined the retailer's optimal order quantity and the optimal selling price simultaneously when the supplier offers free shipping and the retailer faces stochastic demand. Shao [27] investigated the impact of shipping policies in the multiretailer and exclusive retailer supply chains. Song et al. [28] designed a coordination mechanism between an online retailer and a delivery operator for optimizing the threshold pricing. ComScore [8] found that $42 \%$ of online shoppers in Asia added items to their shopping carts in order to qualify for free shipping. So more and more e-commerce platforms have used free shipping to attract online consumers' shopping in order to improve the platforms' performance $[9,10]$. However, the loss due to free transportation is so huge that the promotion is not profitable.

There are many ways to improve the sales volume of enterprises, such as coupons and discount strategies [29, 30]. However, the discount of the product will affect the brand of goods, and the shipping-fee discount will not. The extant literature indicates that the optimization of the transportation costs is significant enough to improve the sales volume of e-tailers [4, 31]. However, even though researchers can detect such effects from the shipping fee, there is no guideline regarding the shipping fee and the best set of products to recommend. This is the focal point of this paper.

2.2. Online Recommendation Systems. Since the first online recommendation system (ORS) was developed by Goldberg and colleagues [32], various recommendation systems and related technologies such as content-based filtering (CBF) and collaborative filtering $(\mathrm{CF})$ have been reported.

Hence, most of the online recommendation systems, according to the customers' online history, are based on CBF or CF approaches to identify the customer's preferences and to recommend the products that are most likely to be accepted for a particular customer [15, 33]. Some research ensured the accuracy of recommendations by improving the accuracy of the algorithm [34]. Different from the CF and CBF methods, which are based on the possibility of buying the product, other research focuses on the impact of the recommendation system on the customer's purchase decision. The researchers also explored the reaction of customers to the recommended products [35] and identified the most appropriate products to recommend $[36,37]$. In addition to customers' preferences, customers' savings, and the e-tailer's profits have emerged. Garfinkel et al. [38] proposed a shopbot to identify the savings opportunities for customers when considering different promotion strategies. Jiang et al. [30] studied the promotion strategy for e-business competitiveness through pricing and recommendation based on 
B2C e-commerce platform. But it was limited in C2C sites because the factors that influence the consumers' purchasing decisions are often different on the different network platform as mentioned in the Introduction. We take Taobao $\mathrm{C} 2 \mathrm{C}$ network platform as the research object and provide a valuable model for managers to optimize the use of online functions to serve customers and improve the sales volume of e-tailers. At the same time, Taobao's e-tailers different from the Amazon platform have more options in the choice of recommended products and the shipping-fee discount. Generally, objective function, the constraints, and models constructed in this paper are different. This paper proposes models to improve the sales volume of e-tailers through optimizing the discount of shipping fee and the decision of product recommendation simultaneously.

In short, current research seldom combines recommendation system with freight to maximize sales volume. This article regards the recommendation system as a marketing means rather than information technology to change consumer behavior and promote sales volume. The paper explores the relationship between recommendation and shipping fee and how to use both simultaneously to maximize sales.

\section{Modeling}

3.1. Modeling Idea. In order to attract consumers to buy recommended products by using the shipping-fee discount, the paper proposes the model shown in Figure 2. When consumers browse the products they need on the Internet, some consumers give up buying the products due to freight. In order to retain these customers, we discount the freight. At the same time, the recommendation system provides other products to consumers according to the browsing history, product-buying history, and consumer information. Then, each of the recommended products and the product with shipping-fee discount are tied to calculate the discount rate of shipping fee. Because the product's shipping fee is lower than the original shipping costs, consumers can always get additional savings from the subsequent shopping process. This model attracts consumers through freight discounts and then compensates for the losses caused by freight discounts by recommending suitable products and ultimately maximizes sales. The basic idea of the model is shown in Figure 2.

\subsection{Foundational Assumptions}

3.2.1. Rationale of the Shipping-Fee Discount. The shippingfee discount is one of the most effective communication links between e-tailers and customers. Before discussing the details of the model, we provide the basic and necessary assumptions. First, the e-tailer collaborates with shipping companies to reduce costs. They get the lowest shipping cost. Second, an e-tailer could price the shipping fee low enough to attract a reasonable number of customers. Finally, we assume that the shipping-fee schedules before the discount derives optimal profits when the product is sold independently.
3.2.2. Rationale of the Recommendation. Offering online recommendation services helps improve customer satisfaction $[15,16]$. Product recommendations can make up for the losses from the free shipping. For example, when a customer is viewing a coat, he can also see other products via the product recommendation. This article contends that the recommendation enhances the customers' awareness and changes the customers' valuation by recommending products to customers who are interested in the promoted items and by analyzing the customers' purchase decision when they view the recommendation. In this paper, consumers can buy any product, regardless of whether it is recommended or not.

3.2.3. Rationale of the Sales Volume. In this study, we assume that the maximizing sales volume by establishing the best shipping-fee discount and recommendation is the goal of the enterprise. Rational consumers will buy due to the surplus value of the products. The sales volume is the additional demands that the proposed model generates. Based on this definition, the strategy changes the e-tailer's sales volume from the following two aspects:

(1) Sales volume changes from the product $f$, which receives a shipping-fee discount

(2) Additional sales from relative products. Customers that are attracted by the product $f$ may also buy other recommended products due to the shippingfee discount.

3.2.4. Rationale of the Gains. The goal of this paper is to pursue the maximization of sales volume, rather than profit maximization. In 1959, Baumol put forward the "sales maximization hypothesis" in the book "Enterprise behavior, value and growth." Baumol regards the maximization of sales under a certain profit's condition as the typical target of an oligopoly. In this paper, the profit constraint is set as follows: the total profit is not less than the profit before the promotion. The gains are the additional profits that the proposed model generates. As long as the gain $\geq 0$, it meets the constraints.

3.3. Model Parameters. The variables used in this paper are shown in Table 1. The following is a detailed description of the variables used in the model. Let us suppose that the current price, cost, and reservation price of product $f$ are $p, c$, and $R_{f}$. "Consumers have different reserve prices for different products" has been widely recognized in the field of marketing [39]. Define the price, cost, and reservation price of the shipping fee about $f$ as $p_{s}, c_{s}$, and $R_{s}$, respectively. The substitutes, complements, and independent products of product $f$ are SUB $=\left\{f_{1}^{S}, \ldots, f_{s}^{S}, \ldots, f_{|\mathrm{SUB}|}^{S}\right\}, \quad \mathrm{COM}=\left\{f_{1}^{C}, \ldots, f_{c}^{C}, \ldots\right.$, $\left.f_{|\mathrm{COM}|}^{C}\right\}$, and $\mathrm{IND}=\left\{f_{1}^{I}, \ldots, f_{i}^{I}, \ldots, f_{|\mathrm{IND}|}^{I}\right\}$, respectively. Among them, $|\mathrm{SUB}|,|\mathrm{COM}|$, and $|\mathrm{IND}|$ are their corresponding numbers. The sales prices of the products are $\left\{p_{1}^{S}, \ldots, p_{s}^{S}, \ldots, p_{|\mathrm{SUB}|}^{S}\right\}, \quad\left\{p_{1}^{C}, \ldots, p_{c}^{C}, \ldots, p_{|\mathrm{SUB}|}^{\mathrm{C}}\right\}, \quad$ and $\left\{p_{1}^{I}, \ldots, p_{i}^{I}, \ldots, p_{|\mathrm{IND}|}^{I}\right\}$. The costs are $\left\{c_{1}^{S}, \ldots, c_{s}^{S}, \ldots, c_{|\mathrm{SUB}|}^{S}\right\}$, 


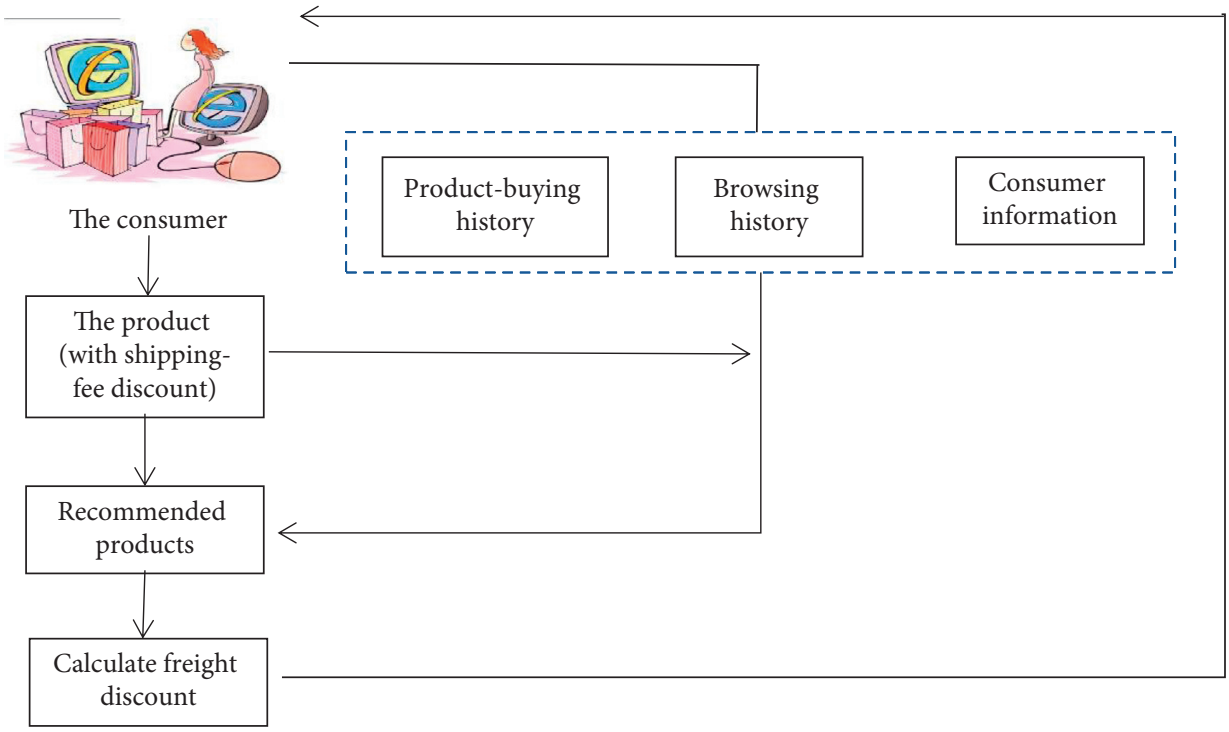

FIgURE 2: Process of the proposed model.

TABle 1: Model parameter.

\begin{tabular}{|c|c|}
\hline $\begin{array}{l}\text { Variable } \\
\text { name }\end{array}$ & Description \\
\hline$N$ & The number of potential customers \\
\hline$m$ & $\begin{array}{l}\text { The maximum number of products that can be } \\
\text { recommended }\end{array}$ \\
\hline$f$ & The product (with shipping-fee discount) \\
\hline$p$ & The price of the product $f$ \\
\hline$c$ & The cost of the product $f$ \\
\hline$R_{f}$ & Customer's reservation price of product $f$ \\
\hline$p_{s}$ & The current shipping fee of product $f$ \\
\hline$c_{s}$ & The cost of shipping fee \\
\hline$R_{s}$ & Customer's reservation price of shipping fee \\
\hline SUB & The set of substitutes of product $f$ \\
\hline$f_{s}^{S}$ & The substitute of product $f, s=1, \ldots,|\mathrm{SUB}|$ \\
\hline |SUB & Total number of substitutes for product $f$ \\
\hline$p_{s}^{S}$ & The price of product $f_{s}^{S}, s=1, \ldots,|\mathrm{SUB}|$ \\
\hline$c_{s}^{S}$ & The cost of the product $f_{s}^{S}$ \\
\hline$R_{s}^{S}$ & Customer's reservation price of $f_{s}^{S}$ \\
\hline$R_{s}^{S, r}$ & $\begin{array}{c}\text { Customer's reservation price of product } f_{s}^{S} \text { with } \\
\text { recommendation }\end{array}$ \\
\hline COM & The set of complements of product $f$ \\
\hline & The complement of product $f, c=1, \ldots,|\mathrm{COM}|$ \\
\hline |COM & Total number of complements for product $f$ \\
\hline & The price of product $f_{c}^{C}, c=1, \ldots,|\mathrm{COM}|$ \\
\hline$c_{c}^{C}$ & The cost of the product $f_{c}^{C}$ \\
\hline$R_{c}^{C}$ & Customer's reservation price of product $f_{c}^{C}$ \\
\hline$R_{c}^{C, r}$ & $\begin{array}{c}\text { Customer's reservation price of product } f_{c}^{C} \text { with } \\
\text { recommendation }\end{array}$ \\
\hline IND & The set of independent products of product $f$ \\
\hline$f_{i}^{I}$ & $\begin{array}{l}\text { The independent product relative to product } f \\
\qquad i=1, \ldots,|\mathrm{IND}|\end{array}$ \\
\hline$|\mathrm{IND}|$ & $\begin{array}{c}\text { Total number of independent products relative to } \\
\text { product } f\end{array}$ \\
\hline$p_{i}^{I}$ & The price of product $f_{i}^{I}, i=1, \ldots,|\mathrm{IND}|$ \\
\hline$c_{i}^{I}$ & The cost of product $f_{i}^{I}$ \\
\hline$R_{i}^{I}$ & Customer's reservation price of $f_{i}^{I}$ \\
\hline$R_{i}^{I, r}$ & $\begin{array}{c}\text { Customer's reservation price of product } f_{i}^{I} \text { with } \\
\text { recommendation }\end{array}$ \\
\hline$s v$ & Discount demands of shipping fee in sales volume \\
\hline gain & Profit gains from customers \\
\hline
\end{tabular}

$\left\{c_{1}^{C}, \ldots, c_{c}^{C}, \ldots, c_{|\mathrm{SUB}|}^{C}\right\}$, and $\left\{c_{1}^{I}, \ldots, c_{i}^{I}, \ldots, c_{|\mathrm{IND}|}^{I}\right\}$, respectively. There are $N$ potential consumers to maximize consumer surplus as the goal, who are willing to maximize utility in the purchase by choosing different products. Consumers will only buy the product if the consumer surplus of a product is nonnegative. Customers' reservation prices of the substitutes, complements, and independent products are $\left\{R_{1}^{s}, \ldots, R_{s}^{s}, \ldots, R_{|\mathrm{SUB}|}^{s}\right\}, \quad\left\{R_{1}^{C}, \ldots, R_{c}^{C}, \ldots, R_{|\mathrm{SUB}|}^{C}\right\}, \quad$ and $\left\{R_{1}^{I}, \ldots, R_{i}^{I}, \ldots, R_{|\mathrm{IND}|}^{I}\right\}$, respectively. The reservation price is the intrinsic value of the product for the consumer, but it may vary with the external environment, such as the recommendation system. We use $R_{s}^{S, r}, R_{c}^{C, r}$, and $R_{i}^{I, r}$ to indicate the customers' reservation prices for the recommended products. Space for the recommended products is limited. $m$ is the maximum number of products that can be recommended. $s v$ is defined as the discount demand as change in sales volume of the product (product $f$, complementary products, substitutes, and independent products). gain is the additional profit as mentioned in Section 3.2.4.

To achieve the best effect, e-tailers need to make decisions in the two following areas: (1) based on the current price $p$, determine the optimal discount rate $d$ for the shipping fee of product $f$, and (2) select products from the $\mathrm{S} \cup \mathrm{B}$ (the set of substitutes of product $f$ ), COM (the set of complements of product $f$ ), and IND (the set of independent products of product $f$ ) to recommend the shipping-fee discount, to impact the customers' purchase decisions, and to maximize the overall sales volume. The decision variables are shown in Table 2. The following section details the calculation method for the total sales volume from product $f$ and its complements, substitutes, and independent products.

3.4. Consumer Classifications. This article studies the impacts of combining the shipping-fee discount with the recommendation system on corporate sales volume. We 
TABLE 2: Decision variables.

\begin{tabular}{lc}
\hline Variable name & Description \\
\hline$d$ & The discount rate of shipping fee \\
$X_{s}^{S}$ & The decision variable, which is 1 if the e-tailer recommends $f_{s}^{S}$ and is 0 otherwise \\
$Y_{n}^{f}$ & The decision variable, which is 1 if the customer buys $f$ and is 0 otherwise \\
$Y_{n}^{S}$ & The decision variable, which is 1 if the e-tailer recommends $f_{c}^{C}$ and is 0 otherwise \\
$X_{c}^{C}$ & The decision variable, which is 1 if the e-tailer recommends $f_{i}^{I}$ and is 0 otherwise \\
$X_{i}^{I}$ & The decision variable, which is 1 if the customer buys $f_{c}^{C}$ and is 0 otherwise \\
$Y_{n}^{C}$ & The decision variable, which is 1 if the customer buys $f_{i}^{I}$ and is 0 otherwise \\
$Y_{n}^{I}$ & Theristerise
\end{tabular}

define the discount demand as the change in sales volume of the product (product $f$, complementary products, substitutes, and independent products). Before the shipping-fee discount, we divided customers into 16 groups based on the purchase decision. The results of the consumer classifications are shown in Figure 3. The solid blue arrows indicate the purchase of complementary products, substitutes, and independent products. The opposite direction indicates no purchase occurred. The 8 regions inside the small sphere with the red line indicate that these consumers did not buy product $f$ before the shipping-fee discount. In contrast, the 8 regions inside the large sphere with a black line indicate that these consumers bought product $f$ before the shippingfee discount. We divide the sphere into two parts. The upper part is shown in Figure 4. The lower part is shown in Figure 5. The consumers (i.e., segments $A-D$ and $E-H$ ) who do not buy product $f$ before the shipping-fee discount are attracted by the shipping-fee discount, change their purchase decision, and increase the sales of product $f$. Alternatively, customers (i.e., consumer groups $I-L$ and $M-P$ ) who buy product $f$ before the shipping-fee discount, who may unintentionally be attracted to the recommended substitutes, change and purchase the recommended substitute and reduce product $f$ 's sales volume.

For complements $f_{c}^{C}$ and independent goods $f_{i}^{I}$, consumers in groups $A, B$, and $C$ would also buy related products without the shipping-fee discount. The demand of customers in segments $A, B$, and $C$ for complements $f_{c}^{C}$ and independent goods $f_{i}^{I}$ is not caused by the shipping-fee discount and is thus not considered in the scope of this work. This paper focuses on the change in sales volume caused by the shipping-fee discount and recommendations.

For substitutes, we assume that consumers buy more than one product in a transaction, that is, the consumer can choose two or more products in product $f$ and substitutes $f_{s}^{S}$, $s=1, \ldots,|\mathrm{S} \cup \mathrm{B}|$, where $|\mathrm{S} \cup \mathrm{B}|$ is total number of substitutes for product. For the consumers in group $E-H$ and group $M-P$, e-tailers may increase the consumers' utility of the recommended substitute, to increase the sales volume for substitutes $f_{s}^{S}$. However, the shipping-fee discount may make customers in group $A-D$ and group $I-L$ change their purchase decision, which leads to a decrease in the sales of substitutes $f_{s}^{S}$.

3.5. Model Construction. To maximize total sales volume, e-tailers need to choose the best shipping-fee discount rate and the most reasonable product collection to recommend. Since many factors determine e-tailers' sales volume, and customers' purchasing decision are affected by numerous concerns, we employ a nonlinear mixedinteger programming model to include key determinants and necessary constraints. The model of shipping-fee discount and recommendation (SDR) can be expressed as follows:

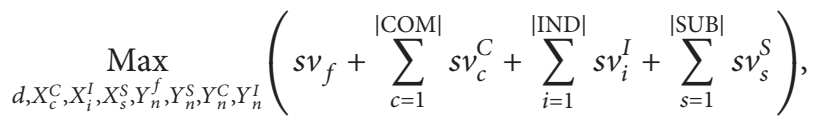

where discount sales of shipping fee for product $f: s v_{f}=\sum_{n=1}^{N} Y_{n}^{f}$, discount sales of shipping fee for complements $f_{c}^{C}: s v_{c}^{C}=\sum_{n=1}^{N} Y_{n}^{C}$, discount sales of shipping fee for product independent goods $f_{i}^{I}: s v_{i}^{I}=\sum_{n=1}^{N} Y_{n}^{I}$, discount sales of shipping fee for substitutes $f_{s}^{S}: s v_{s}^{S}=\sum_{n=1}^{N} Y_{n}^{S}$.

The sales volume from product $f$ is given in constraints (2)-(5). To attract consumers to buy product $f$, the e-tailer must develop the total price of product $f$ and the shippingfee discount, which ensures a consumer surplus. Therefore, when the e-tailer sets up the shipping-fee discount, the reservation prices of customers who would buy product $f$ satisfy the following constraint:

$$
\left[R_{f}+R_{s}-\left(p+p_{s} \times(1-d)\right)\right] Y_{n}^{f} \geq 0, \quad n=1, \ldots, N .
$$

The consumer's reservation price is an important factor in deciding whether to buy the product and at what price to buy the product $f$. The reservation price determines the different consumer responses to the shipping-fee discount. $s v_{f}$ (discount sales of shipping fee for product $f$ ) is mainly from two different types of customers with different reactions.

(1) The first class of consumers in segments $A-D$ and segments $E-H$ did not purchase product $f$ before the shipping-fee discount, but they may choose to buy product $f$ when a shipping-fee discount is offered. The reservation prices of consumers satisfy the following constraints:

$$
\left[p+p_{s}-\left(R_{f}+R_{s}\right)\right]_{n}^{f} \geq 0, \quad n=1, \ldots, N .
$$

$s v_{A-\mathrm{D}, \mathrm{E}-\mathrm{H}}$ is the sales volume that e-tailers use the shipping-fee discount to increase, and it generates additional gains: 


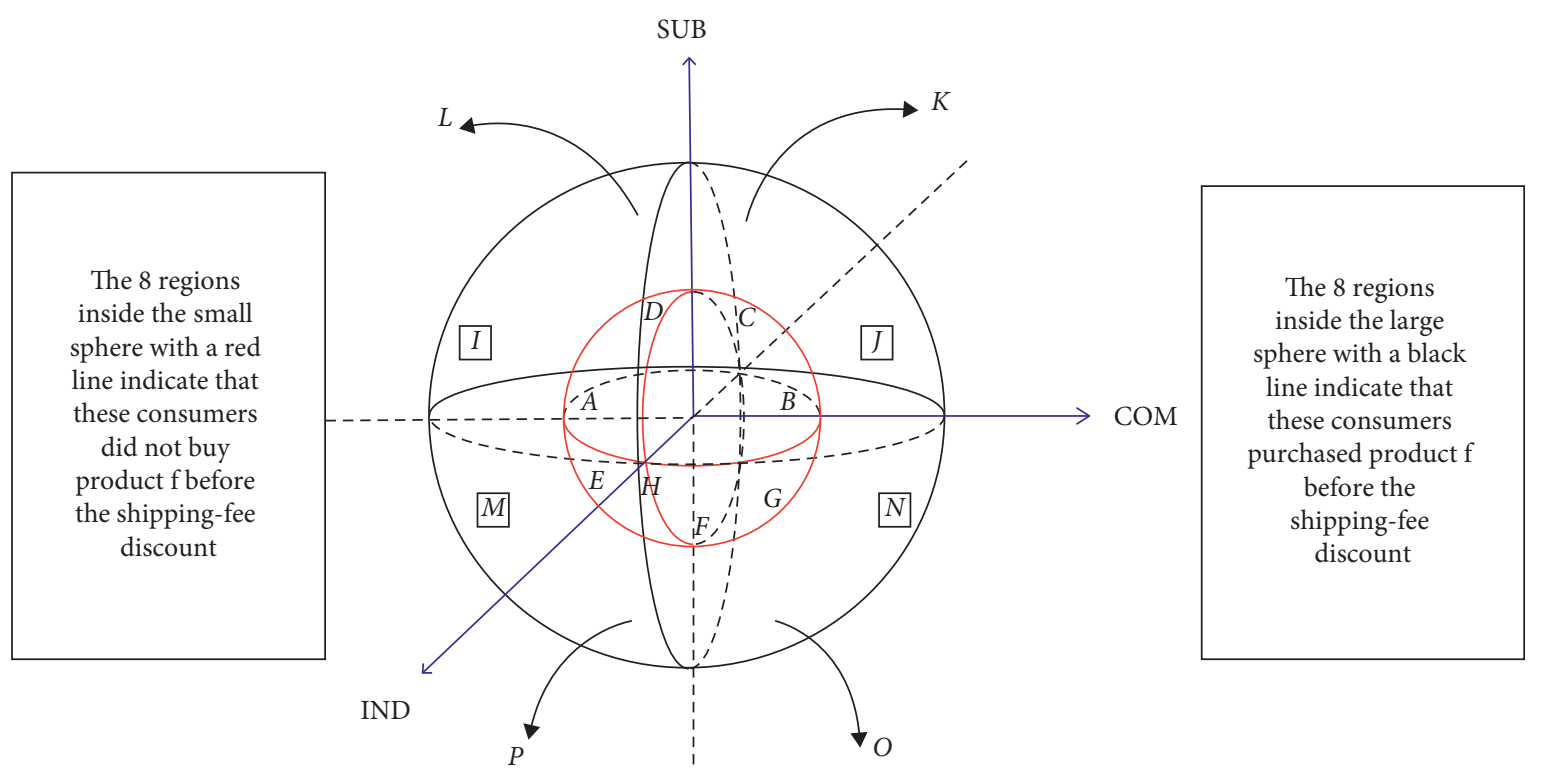

Figure 3: Consumer classifications based on purchase decision.

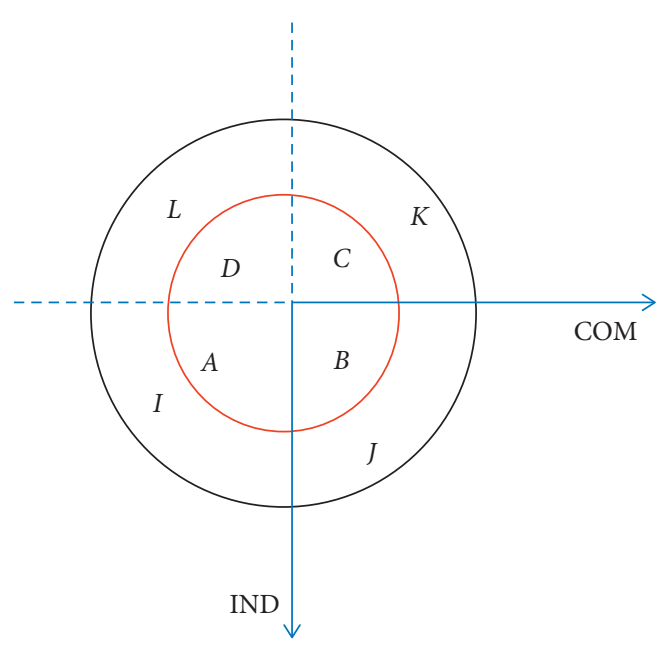

FIgURE 4: The upper part of the sphere.

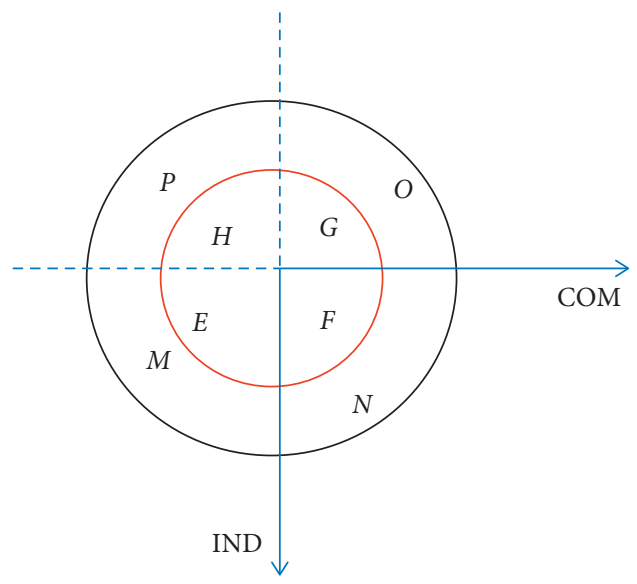

FIgURE 5: The lower part of the sphere.
$\operatorname{gain}_{A-D, E-H}=\left\{\left[p+p_{s} \times(1-d)\right]-\left(c+c_{s}\right)\right\} \times s v_{A-D, E-H}$.

(2) The second type of consumers decided to buy product $f$ before the discount activities in segments $I-L$ and segments $M-P$. The consumer's reservation price satisfies the following constraint:

$$
\left[R_{f}+R_{s}-\left(p+p_{s}\right)\right] Y_{n}^{f} \geq 0, \quad n=1, \ldots, N .
$$

The constraint (5) indicates that the total reservation price is higher than the sum of the price of the product $f$ and the current shipping fee of product $f: p+p_{s}$ in consumer groups $I-L$ and $M-P$. The corresponding profits from these customers are as follows:

$$
\begin{aligned}
\operatorname{gain}_{I-L, M-P}= & {\left[p+p_{s} \times(1-d)-\left(c+c_{s}\right)\right] \times s v_{I-L, M-P} } \\
& -\left[p+p_{s}-\left(c+c_{s}\right)\right] \times s v_{I-L, M-P} \\
= & -p_{s} \times d \times s v_{I-L, M-P} .
\end{aligned}
$$

In summary, the gain from product $f$ under the shipping-fee discount is given by

$$
\begin{aligned}
\text { gain } f= & {\left[p+p_{s} \times(1-d)-c-c_{s}\right] \times s v_{A-D, E-H} } \\
& -p_{s} \times d \times s v_{I-\mathrm{L}, \mathrm{M}-\mathrm{P}} .
\end{aligned}
$$

The sales volume from complementary products is given in constraints (8)-(12). Due to the complementary effect, the consumers' e-decision to purchase complementary goods may change because of the shipping-fee discount. The main sales volume from complementary products is in two categories of consumers, as follows:

(1) The customers in segments $I, L, M$, and $P$ buy product $f$ without complements $f_{c}^{C}$ before the 
shipping-fee discount, whose reservation prices of $f$ satisfy the constraint (5). In addition, the product bundle $\left\{f, f_{c}^{C}\right\}$ cannot bring consumers more surplus utility $\left(\left(R_{f_{c}}^{C}+R_{s}-p-p_{c}^{C}-p_{s}\right)<\left(R_{f}+R_{s}-\right.\right.$ $\left.\left.p-p_{s}\right)\right)$. Nevertheless, the shipping-fee discount and product recommendation may change the relationship between consumers' reservation price of the bundle and the bundle price. Therefore, the possibility of $\left(\left(R_{f c}^{C, r}+R_{s}-p-p_{c}^{C}-p_{s} \times(1-d)\right) \geq\right.$
$\left.\left(R_{f}+R_{s}-p-p_{s}\right)\right)$ exists when complements $f_{c}^{C}$ is recommended. When e-tailers recommended complements $f_{c}^{C}$, the customers' reservation price for product bundle $\left\{f, f_{c}^{C}\right\}$ is $R_{f c}^{C, r}$, otherwise $R_{f c}^{C}$. The constraints of these consumers' reservation price are as follows:

$$
\begin{array}{r}
{\left[\left(R_{f}+R_{s}-p-p_{s}\right)-\left(R_{f c}^{C}+R_{s}-p-p_{c}^{C}-p_{s}\right)\right] Y_{n}^{C} \geq 0, \quad n=1, \ldots, N,} \\
{\left[\left(R_{f c}^{C, r}+R_{s}-p-p_{c}^{C}-p_{s} \times(1-d)\right) X_{c}^{C}-\left(R_{f}+R_{s}-p-p_{s}\right)\right] Y_{n}^{N} \geq 0, \quad n=1, \ldots, N .}
\end{array}
$$

The gains of the complements from these customers are as follows:

$$
\operatorname{gain}_{I, L, M, P}=\left(p_{c}^{C}-c_{c}^{C}\right) \times s v_{I, L, M, P} .
$$

The reservation prices $R_{f_{c}}^{C}$ and $R_{f_{c}}^{C, r}$ have an important influence on the purchase decision of complements $f_{c}^{C}, c=1, \ldots,|\mathrm{COM}|$. For the bundle of independent products, e-tailers can calculate the independent products' reservation price by adding them together, as consumers' reservation prices are independent of each other [40], whereas for the bundle of complementary products and consumers' superadditive reservation prices, enterprises can use the method from the literature $[41,42]$ for the calculation. Section 5 adopts sensitivity analysis to introduce the effect of reservation price changes.

(2) The consumers buy neither product $f$ nor complements $f_{c}^{C}$ before the shipping-fee discount, whose reservation prices for $f$ satisfy the constraint (3) and reservation prices for complements $f_{c}^{C}$ satisfy $R_{c}^{C}<p_{c}^{C}$. In the process of the shipping-fee discount, consumers buy the products $f$ since their reservation prices meet the constraint (2). If the products complementary effect and personalized recommendation increase the consumer's reservation price of complements $f_{c}^{C}$, the purchase of bundle $\left\{f, f_{c}^{C}\right\}$ can produce more surplus utility. The customers' reservation prices satisfy $\left(\left(R_{f c}^{C, r}+R_{s}-p-p_{c}^{C}-p_{s} \times\right.\right.$ $\left.(1-d)) \geq\left(R_{f}+R_{s}-p-p_{s}\right)\right)$ when complements $f_{c}^{C}$ are recommended and satisfy $\left(R_{f c}^{C}+R_{s}-p-\right.$ $\left.p_{c}^{C}-p_{s} \times(1-d)\right) \geq\left(R_{f}+R_{s}-p-p_{s}\right)$ when complements $f_{c}^{C}$ are not recommended. Therefore, the consumers may continue to buy complements $f_{c}^{C}$ and their reservation prices satisfy the following constraints:

$$
\begin{aligned}
& \left(p_{c}^{C}-R_{c}^{C}\right) Y_{n}^{C} \geq 0, \quad n=1, \ldots, N \\
& {\left[\left(R_{f c}^{C, r}+R_{s}-p-p_{c}^{C}-p_{s} \times(1-d)-\left(R_{f}+R_{s}-p-p_{s}\right)\right) X_{c}^{C}\right]} \\
& \quad \times\left[-\left(R_{f c}^{C}+R_{s}-p-p_{c}^{C}-p_{s} \times(1-d)-\left(R_{f}+R_{s}-p-p_{s}\right)\right) \times\left(1-X_{c}^{C}\right)\right] Y_{n}^{C} \geq 0, \quad n=1, \ldots, N .
\end{aligned}
$$

The corresponding gains from these customers are as follows:

$$
\operatorname{gain}_{A, D, H, E}=\left(p_{c}^{C}-c_{c}^{C}\right) \times s v_{A, D, H, E}
$$

In summary, e-tailers' gains from complementary goods $f_{c}^{C}$ can be summarized as follows:

$$
\begin{aligned}
\operatorname{gain}_{c}^{C} & =\operatorname{gain}_{I, L, M, P}+\operatorname{gain}_{A, D, H, E} \\
& =\left(p_{c}^{C}-c_{c}^{C}\right) \times\left(s v_{I, L, M, P}+s v_{A, D, H, E}\right) .
\end{aligned}
$$

The sales volume from independent products is given in constraints (15)-(18). Similar to the complementary products, e-tailers obtain the sales volume from segments $C, D, L$, $K, H, G, P$, and $O$ buying independent products $f_{i}^{I}$. 


$$
\begin{array}{rr}
{\left[\left(R_{f}+R_{s}-p-p_{s}\right)-\left(R_{f}+R_{i}^{I}+R_{s}-p-p_{s}-p_{i}^{I}\right)\right] Y_{n}^{I} \geq 0,} & n=1, \ldots, N, \\
{\left[\left(R_{f}+R_{i}^{I, r}+R_{s}-p-p_{s} \times(1-d)-p_{i}^{I}\right) \times X_{i}^{I}-\left(R_{f}+R_{s}-p-p_{s}\right)\right] Y_{n}^{I} \geq 0,} & n=1, \ldots, N \\
\left(p_{i}^{I}-R_{i}^{I}\right) Y_{n}^{I} \geq 0, & n=1, \ldots, N, \\
{\left[R_{f}+R_{i}^{I, r}+R_{s}-p-p_{s} \times(1-d)-p_{i}^{I}-\left(R_{f}+R_{s}-p-p_{s}\right)\right] Y_{n}^{I} \geq 0,} & n=1, \ldots, N .
\end{array}
$$

The reservation price $R_{i}^{I, r}$ is the consumer evaluation of the product when e-tailers recommended independent goods $f_{i}^{I}$. The e-tailer's gains from independent goods $f_{i}^{I}$ can be summarized as follows:

$$
\operatorname{gain}_{i}^{I}=\left(p_{i}^{I}-c_{i}^{I}\right) \times\left(s v_{L, K, P, O}+s v_{C, D, H, G}\right) .
$$

The sales volume from substitutes is given in constraints (20)-(27). If the shipping-fee discount of $f$ products can bring consumers more utility, consumers in segments $A, B$, $C$, and $D$ may abandon the purchase of substitutes and buy product $f$. This type of consumer's reservation price satisfies constraints (2), (3), and (20)-(22). Among them, constraints (3) and (20)-(22) indicate that consumers belong to groups $A, B, C$, and $D$; the constraint (2) shows that consumers will buy product $f$ instead of the substitutes in the shipping-fee discount activities:

$$
\begin{array}{r}
\left(R_{s}^{S}-p_{s}^{S}\right) Y_{n}^{S} \geq 0, \quad n=1, \ldots, N, \\
{\left[R_{s}^{S}-p_{s}^{S}-\left(R_{f}-p\right)\right] Y_{n}^{S} \geq 0, \quad n=1, \ldots, N,}
\end{array}
$$

$\left[R_{f}+R_{s}+R_{f c}^{S, r}-p-p_{s}^{S}-p_{s} \times(1-d)\right] Y_{n}^{S} \leq 0, \quad n=1, \ldots, N$.

Due to the substitution effect, the change in the consumers' purchase decision reduces the sales volume of substitutes $f_{s}^{S}$. The reductive gains are shown as follows:

$$
\operatorname{gain}_{A-D}=-\left(p_{s}^{S}-c_{s}^{S}\right) \times s v_{A-D} .
$$

For groups $I-L$, if the e-tailers' recommendations increase the consumer's reservation price, the purchase of substitutes $f_{s}^{S}$ has the highest positive consumer surplus compared with the other substitutes. Therefore, customers may change their original purchase decision and increase the demand of substitutes $f_{s}^{S}$. These consumers' reservation prices meet the following constraints:

$$
\begin{aligned}
& {\left[R_{s}^{S}+R_{f}+R_{s}-p-p_{s}^{S}-p_{s}-\left(R_{s}^{S}+R_{s}-p-p_{s}^{S}\right)\right] Y_{n}^{S} \leq 0, \quad n=1, \ldots, N,} \\
& {\left[R_{s}^{S, r}+R_{f}+R_{s}-p-p_{s}^{S}-p_{s} \times(1-d)\right]} \\
& \times\left[R_{f}+R_{s}+R_{f c}^{S, r}-p-p_{s}^{S}-p_{s} \times(1-d)-\left(R_{f c}^{S, r}+R_{s}-p_{s}^{S}-p_{s}\right)\right] Y_{n}^{S} \geq 0, \quad n=1, \ldots, N .
\end{aligned}
$$

The corresponding gain of substitutes $f_{s}^{S}$ in segments $I-L$ is given by

$$
\text { gain } I-L\left(p_{s}^{S}-c_{s}^{S}\right) \times s v_{I-L} .
$$

In addition, customers in segments $E-H$ impacted by the recommendation may purchase substitutes $f_{s}^{S}$. The corresponding consumers meet the constraints (3) and (27):

$$
\left[R_{s}^{S}+R_{s}-p_{s}^{S}-p_{s}\right] Y_{n}^{S} \leq 0, \quad n=1, \ldots, N .
$$

Constraint (27) indicates that customers would not buy the product if their surpluses are negative. The corresponding gains of the consumers are as follows:

$$
\text { gain } E-H=\left(p_{s}^{S}-c_{s}^{S}\right) \times s v_{E-H} .
$$

In summary, the e-tailer's gains from product $f_{s}^{S}$ are as follows:

$$
\begin{aligned}
\operatorname{gain}_{s}^{S} & =\operatorname{gain}_{I-L}+\operatorname{gain}_{E-H}+\operatorname{gain}_{A-D} \\
& =\left(p_{s}^{S}-c_{s}^{S}\right) \times\left(s v_{I-L}+s v_{E-H}-s v_{A-D}\right) .
\end{aligned}
$$

The constraint (30) indicates that the profit after the promotion shall not be less than the profit before the promotion:

$$
\operatorname{gain}_{f}+\sum_{c=1}^{|\mathrm{COM}|} \operatorname{gain}_{c}^{C}+\sum_{i=1}^{|\mathrm{IND}|} \operatorname{gain}_{i}^{I}+\sum_{s=1}^{|\mathrm{SUB}|} \operatorname{gain}_{s}^{S} \geq 0 .
$$

Model constraint (31) shows that e-tailers cannot recommend all products. Under the traditional environment (such as the physical store), the limited shelf space makes the e-tailer arrange products that have the highest profits and are most likely to be purchased on the shelf. Under the network environment, the maximum recommended amount $m$ is mainly affected by the space of the recommended list or online ads: 


$$
\sum_{c=1}^{|\mathrm{COM}|} X_{c}^{C}+\sum_{i=1}^{|\mathrm{IND}|} X_{i}^{I}+\sum_{s=1}^{|\mathrm{SUB}|} X_{s}^{S} \leq m
$$

\section{Experimental Results}

To verify the effectiveness of the proposed model, we use a Taobao shop's data to analyze the improvement effect of the model on e-tailers' sales volume. The focus of this manuscript is to emphasize the importance of the joint optimization of the discount rate and product recommendation. Therefore, the model with joint optimization should be compared with strategies that optimize only one component. On the one hand, we confirm the validity of the proposed model by comparison with a strategy with an optimal discount and random recommendation and a strategy with no discount but optimal recommendation. On the other hand, we change the shipping-fee discount and recommendation products collection to study the relationship between the shipping-fee discount and product recommendation.

\subsection{Data Sources}

4.1.1. Data Collection. In the Taobao shop, the "mop" was promoted with the shipping-fee discount, and online shop owners provided product recommendations to consumers. According to Figure 1, the enterprise can recommend 6 products to consumers. How are 6 products selected to recommend? This model initially selects products from the whole store for recommendation. So we collect the original price of the product, the shipping-fee discount, recommended products' (SUB, COM, and IND) price, and other data. We can also obtain the product's cost from the e-tailer in the experiment. Recommended products and their relationship to the mop are shown in Table 3. These are candidate sets of recommended products.

4.1.2. Customers' Reservation Prices. Because the online shop's sales price is the result of continuous improvement in the fierce market competition environment, this article assumes that the product price is the best price for each product sold separately. Previous research has provided a reliable method of simulating the consumer's reservation price based on the optimal price of the product [24, 30, 43]. For example, when the consumer reservation price is subject to the uniform distribution $U\left(r_{l}, r_{u}\right)$, the optimal price of the product $p$ is the mean of the product cost and the upper bound of the reservation price, namely, $p=((r u+c) / 2)$. Jiang et al. [29] used this approach to estimate the distribution range of customers' reservation prices and obtained satisfactory results. We can get the upper bound of the reservation price $r_{u}=2 \times p-c$. We assume that the lower bound of the reservation price is a certain percentage of the product price: $r_{l}=(1-\beta) \times p$, where $\beta$ measures the degree of heterogeneity in the customers' valuation of the product. In this chapter, we first assume that the value of $\beta$ is 0.2 . Then, the effect of $\beta$ and the type of consumer reservation
TABLE 3: Recommended products and their relationship to mop.

\begin{tabular}{lcc}
\hline ID & Product name & Relation \\
\hline F1 & Blue mop & SUB \\
F2 & Long mop & SUB \\
F3 & Rotary mop & SUB \\
F4 & All-match mop & SUB \\
F5 & Mop rod & COM \\
F6 & Mop head & COM \\
F7 & Matching gloves & COM \\
F8 & Cleaning agent & COM \\
F9 & Car brush & IND \\
F10 & Garbage bag & IND \\
F11 & Glass blowing & IND \\
F12 & Broom & IND \\
\hline
\end{tabular}

price (normal distribution, exponential distribution, and web distribution) are studied in Section 5.

4.1.3. Experimental Design. Based on the literature [42, 44], we assume that the consumer's reservation price for the complementary products bundle $R_{f_{c}}^{C}$ is $R_{f}+\left(1+\theta_{f_{c}}^{C}\right) \times R_{c}^{C}$, where the complementarity index $\theta_{f c}^{C}$ is the random number in the interval $[0,0.1]$. The customers' reservation price for substitute $R_{s}^{S, r}$ equals $(1+\gamma) \times R_{s}^{S}$ when recommended, where $\gamma$ is an influence index. We will study the effect of $\theta_{f_{c}}^{C}$ and $\gamma$ on the proposed model by sensitivity analysis in Section 5 .

In this chapter, we verify the effectiveness of the optimization model by three experiments and assume that the number of consumers $N$ is 500 and the maximum number of products recommended $m$ is 6 . Experiment 1 was a study conducted with only shipping discounts and no recommended products. Experiment 1 proved that sales volume can be increased through freight discount, but the loss of freight would reduce the profit within a certain range. The results of experiment 2 verified the overall performance of the model, optimizing the shipping-fee discounts and recommended product set to get the best sales volume and comparing them with the methods that optimize only one component. Experiment 3 changed the discount rate and recommended product collection to verify the dependencies of the discount and the product recommendation.

\subsection{Numerical Results}

4.2.1. Loss of Freight Discount. We base our profit on the absence of any marketing measures. That is, when gain $=0$, there are no shipping discounts and recommendation strategies. In Experiment 1, a freight discount is randomly selected to calculate the sales volume and profit. The experimental result is that the sales volume of product $f$ is 67 , which means that the freight discount brings an increase in products. At this time gain $>0$, that is, the freight discount makes consumers buy more product $f$ and also brings profits to the merchant. Next, we increase the shipping discount to $78 \%$. The experiment finds that the sales volume increases, but gain $<0$, indicating that the loss caused by the freight discount is greater than the profit brought by the increase in the sales volume of product $f$. At this time, in the case of the freight discount, we made product 
recommendations and find an increase in sales and profit compared to shipping discounts alone. The results show that product recommendation can to some extent compensate for the impact of freight discounts. And sales and profits change with different recommended products. The focus of this article is to study how to optimize freight discounts and recommend products to maximize sales when gain $\geq 0$. Next, we perform experiments 2 and 3.

4.2.2. Overall Performance. We examine the gains of the enterprise using the optimization model and compare it with the sales volume from the following strategies: (1) NDOR strategy (No Discount but Optimal Recommendation): NDOR does not set the discount rate of the shipping fee with optimal recommended products; and (2) ODRR strategy (Optimal Discount and Random Recommendation). In ODRR, e-tailers attract consumers to buy products with the highest profit margins, which is a widely used marketing practice. In this paper, the ODRR strategy assumes that the e-tailers set the shipping-fee discount from the SDR and choose 6 products with minimum cost ratios from $S \cup B$, $\mathrm{COM}$, and IND as the recommended products.

$\mathrm{SDR}$ is the method proposed in this paper. According to the steps in Figure 2, first find the product $f$ satisfying consumer demand. Through the model proposed in Section 3, then calculate 6 products meeting the constraints and recommend them to consumers. These 6 products are selected from the products $(S \cup B, C O M$, and IND) in Table 1 . Through experiments, we find that the model can significantly improve the sales volume compared with the NDOR and ODRR strategies. The sales volume from different strategies is shown in Table 4 . Table 4 shows that the effect of the proposed method is better than that of NDOR and ODRR. The sales volume improvements are 52.8\% ((2104-1377)/1377) and $10.2 \%((2104-1910) / 1910)$, respectively.

For the NDOR strategy, e-tailers forego the opportunity to guide the consumers' purchasing decisions using the most suitable shipping-fee discount. Therefore, they lose the potential sales volume. Consumers may forego a purchase because of the expensive shipping fee, such as in the scenario with Dasiy that was mentioned in the Introduction. In ODRR, the product with the maximum profit margin does not necessarily meet the individual needs of consumers, so it is difficult for e-tailers to obtain the highest sales volume.

\subsubsection{Dependence of the Shipping-Fee Discount and Optimal} Recommendation. Dependence of the shipping-fee discount and optimal recommendation requires the e-tailers' systematic consideration. We take the mop and products shown in Table 3 as an example to verify the necessity of simultaneously considering the shipping-fee discount and product recommendations. Based on the proposed model, we find that the optimal discount rate of the shipping fee is $58 \%$ and the optimal set to recommend is $\{\mathrm{F} 3, \mathrm{~F} 5, \mathrm{~F} 6, \mathrm{~F} 7$, F10, F12\}. To understand the importance of the discount rate, we recommended a set of products based on the model and change the discount rate in the range of $[50 \%, 60 \%]$. Figure 6 shows the corresponding sales volume for product
TABLE 4: Comparison of demand between SDR and other strategies.

\begin{tabular}{lccccc}
\hline strategy & The product & SUB & COM & IND & Total \\
\hline NDOR & -44 & 48 & 721 & 652 & 1377 \\
ODRR & 271 & -213 & 1131 & 721 & 1910 \\
SDR & 302 & -241 & 1231 & 812 & 2104 \\
\hline
\end{tabular}

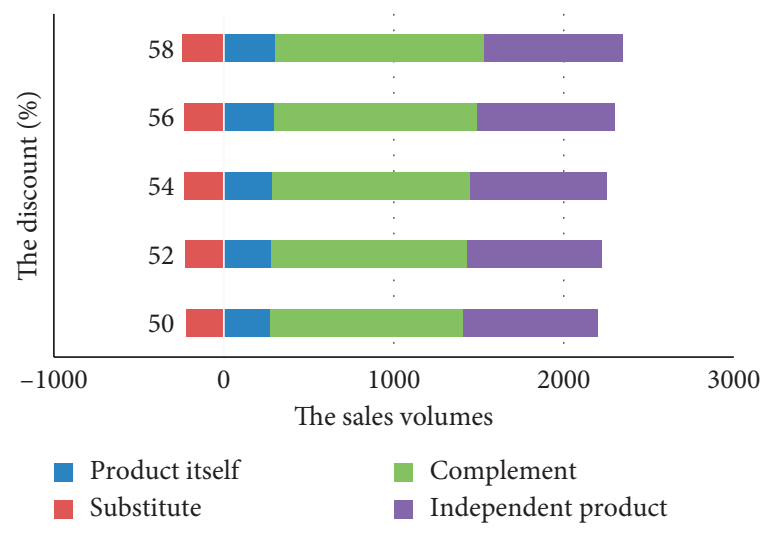

Figure 6: Sales volume under different discount rates.

$f$, complement $f_{c}^{C}$, independent product $f_{i}^{I}$, and substitute $f_{s}^{S}$ with different shipping-fee discounts applied.

Figure 6 shows that e-tailers obtain more sales volume with the increase of the discount rate. Although the discount attracted more new customers, it has decreased the gains. There is the constraint gain $\geq 0$, so the discount cannot continue to increase. These new customers buy product $f$, complementary products $f_{c}^{C}$, and independent products $f_{i}^{I}$, increasing sales. However, when the discount rate is more than $58 \%$, even though the discount attracts more customers, it is difficult to satisfy the constraint gain $\geq 0$. From Figure 6, we see the following: given the recommended products set, there exists an optimal discount to cause the largest sales volume for the e-tailer.

To understand the necessity of recommending the right products, we vary the recommendation set when the shipping-fee discount is fixed at the optimum (58\%). For each product in the optimal recommendation list $\{\mathrm{F} 3, \mathrm{~F} 5, \mathrm{~F} 6, \mathrm{~F} 7$, F10, F12\}, we use the products that belong to the same category and are not in the list to replace it. For example, products (F1, F2, F3, F4) belong to the substitute of product F3. First, we use product F1 to replace product F3. Then, we simulate the sales volume of the new recommendation $\{\mathrm{F} 1$, F5, F7, F8, F10, F12\}. Last, we replace F3 with F2 and F4 and then simulate the corresponding sales volume. Figure 7 gives sales volume and the corresponding recommended products.

Figure 7 shows that the e-tailer cannot obtain the maximum sales volume without the optimal recommendation list. In this case, the largest sales volume the e-tailer can achieve is 2104 . When the e-tailer transforms the best recommended products, the suboptimal gain is less than 2104. From Figure 7, we obtain the following revelation: given the optimal shipping-fee discount rate, e-tailers should recommend a reasonable product set to get the highest sales volume. 


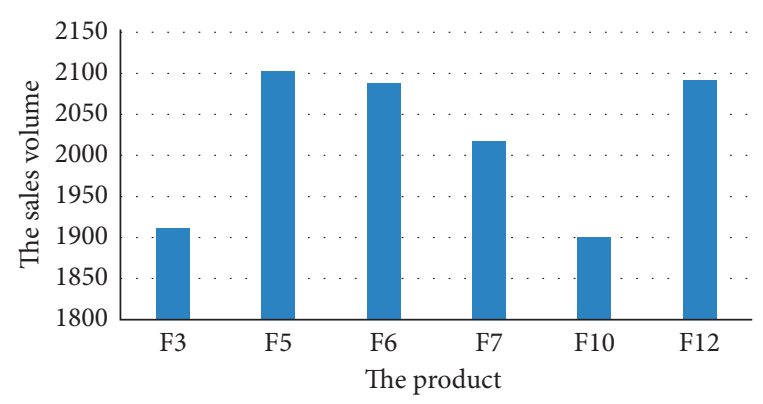

FIGURE 7: Sales volume under different recommendation decisions.

\section{Sensitivity Analysis}

This section changes the reservation price, complementary degree, and dynamic parameters in the reasonable scope to validate the stability of the proposed model in the face of an uncertain environment. Experimental data of 20 products including the before-promotion prices, the complementary, substitute, and independent products and their prices and costs from the recommendation list are from the Taobao online shop. Using the following method to simulate the product reservation price, we get the results of this section based on the average results of the above 20 cases.

5.1. Influence of Reserve Price Distribution Type. The results in this paper are based on the uniform distribution of reservation. The effects of different reservation prices $[45,46]$ are examined in this section. In fact, the consumer's reservation price may have different forms, such as a normal distribution, exponential distribution, Weibull distribution, or mixed distribution. We examined these distribution types as follows. In the case of a normal distribution, we assume that the consumer reservation price distribution is $N\left(u, \sigma^{2}\right)$, with $u=\left(\left(\gamma_{u}+\gamma_{l}\right) / 2\right)$ and $\sigma=\left(\left(\gamma_{u}-\gamma_{l}\right) / 4\right)$. In the case of the exponential distribution, the consumers' reservation price in the range of $\left[\gamma_{l}, \gamma_{u}\right]$ obeys distribution $E(u)$. In the case of the Weibull distribution, the consumers' reservation price is subject to $W(u, 2)$. The real number 2 is the shape parameter, and $u$ is the scale parameter. To make a fair comparison, this paper first calculates the optimal price of the products sold separately when consumers' reservation prices are in accordance with the different distributions. Then, the shipping-fee discount rate and the recommendation list are obtained by using our proposed model. Table 5 shows that the proposed model can achieve higher sales volume regardless of the distribution.

5.2. Changes in the Range of Reservation Prices. Parameter $\beta$ explains the heterogeneity of the consumers' evaluation of products. The greater the $\beta$ is, the greater the difference in the evaluation of products is. The $\beta$ of the product and its related products were changed to verify the influence of the heterogeneity. The $\beta$ of the related products is set at 0.3 , when the $\beta$ of the product changes between 0.1 and 0.5 . Table 6 shows the shipping-fee discount rate and the sales volume. Conversely, when $\beta$ of the related products changes
TABLE 5: Comparison of sales volume between SDR and other strategies under different distribution types.

\begin{tabular}{lccc}
\hline Distribution type & NDOR & ODRR & SDR \\
\hline Normal distribution & 1172 & 1881 & 2218 \\
Exponential distribution & 1503 & 2113 & 2317 \\
Weibull distribution & 1021 & 1501 & 1523 \\
\hline
\end{tabular}

TABLE 6: Impact of the product reservation price alterations.

\begin{tabular}{lcc}
\hline$\beta$ & Discount (\%) & Sales volume \\
\hline 0.1 & 44 & 2188 \\
0.2 & 46 & 2113 \\
0.3 & 48.2 & 2107 \\
0.4 & 51.1 & 1918 \\
0.5 & 54 & 1587 \\
\hline
\end{tabular}

TABLE 7: Impact of the relative product reservation price alterations.

\begin{tabular}{lcc}
\hline$\beta($ COM, IND, and SUB) & Discount $(\%)$ & Sales volume \\
\hline 0.1 & 59.8 & 4101 \\
0.2 & 54.9 & 3701 \\
0.3 & 50.1 & 2107 \\
0.4 & 44 & 1889 \\
0.5 & 42.3 & 1373 \\
\hline
\end{tabular}

TABLE 8: Impact of recommendation.

\begin{tabular}{lcc}
\hline Dynamic parameter $\gamma$ & Discount $(\%)$ & Demand \\
\hline 0.1 & 39.2 & 2259 \\
0.2 & 44 & 3407 \\
0.3 & 48.2 & 4206 \\
0.4 & 50.1 & 4615 \\
0.5 & 51.2 & 4827 \\
\hline
\end{tabular}

between 0.1 and $0.5, \beta$ of the product remains at 0.3 . Table 7 shows the corresponding results.

5.3. Effect of Personalized Recommendation. Studies have shown that an effective recommendation can improve the utility of consumers (or the reservation price) to increase the possibility of the consumers purchasing the product [30]. We vary parameter $\gamma$ from 0.1 to 0.5 , proving the influence of a personalized recommendation. As shown in Table 8, the sales volume increased with the increase of the dynamic parameter $\gamma$.

5.4. The Effect of Products' Complementary. In the study of bundled pricing, the compatibility of the product is commonly measured from 0 to 1 . According to the existing literature [42] and consumer behavior, this paper assumes that the purchase behavior of the product has a positive influence on the consumer evaluation of complementary products. The formula is $R_{f c}^{C}=R f+\left(1+\theta_{f_{c}}^{C}\right) \times R_{c}^{C}$, with $\theta_{f c}^{C}>0$. This section changed $\theta_{f_{c}}^{C}$ from 0.1 to 0.5 , and the results are shown in Table 9. 
TABLE 9: Impact of the complementarity degree.

\begin{tabular}{lcc}
\hline Complementary parameter & Discount (\%) & Demand \\
\hline 0.1 & 43.8 & 1901 \\
0.2 & 46.7 & 2315 \\
0.3 & 47.8 & 2589 \\
0.4 & 49.1 & 3656 \\
0.5 & 51.3 & 3701 \\
\hline
\end{tabular}

\section{Conclusions and Discussion}

E-commerce has greatly improved the efficiency and efficiency of traditional business activities. However, expensive shipping fees prevent customers from completing online transactions, which leads to a loss of sales for e-tailers. More and more e-commerce platforms have used free shipping to attract online consumers' shopping in order to improve the platforms' performance. A dilemma that the collection of transportation costs to compensate for the cost of the e-tailer's transportation often dissuades the customers from purchasing, while reducing the cost of transportation leads to a loss in the e-tailer's profits.

In the era of big data, how to use the recommender system as a marketing tool to promote the sustainable development of enterprises and convert potential browsers into actual buyers? This paper puts forward the optimization model to improve e-tailers' sales volume by setting the shipping discount and recommended products list. Setting a reasonable shipping fee is a difficult task. It not only needs to be low enough to attract consumers but also needs to be high enough to ensure the profits of the e-tailers. The dynamic recommendation of different products under different conditions is also an essential business decision. SDR divides consumers into different categories, combined with product information, and calculates the lowest shipping discount and a recommended product list. The experimental results verify that the proposed model can increase the e-tailers' sales volume by comparing it with other methods. The results also show the dependence between the shipping-fee discount and the optimal recommendation. When the shipping-fee discount of the product is determined, e-tailers should recommend reasonable products to obtain maximum sales volume. Meanwhile, given a set of recommended products, there is an optimal shipping-fee discount that can bring the maximum sales volume.

We use sensitivity analysis to confirm the efficiency of the proposed model under an uncertain environment and find two managerial implications: (1) increasing the shipping-fee discount may lead to sales' decline when consumers have divergent valuations for the related products; (2) a personalized recommendation has an important role in improving the sales volume. Under the high-quality guarantee of the recommendation system, e-tailers can increase sales volume by offering the shipping-fee discount.

Therefore, companies can reduce customer churn through freight discounts and turn potential consumers into actual consumers and then use the recommendation system as a marketing tool to allow consumers to buy more products to make up for the losses caused by freight discounts. The model proposed in this article can optimize freight discounts and recommend products at the same time, so that consumers buy more products and ultimately maximize e-tailers' sales volume to solve the loss of consumers.

\section{Data Availability}

Data come from a shop of Taobao.com. The data used to support the findings of this study were provided by the online shop under license. Access to these data will be considered by the author upon request, with permission of the online shop.

\section{Conflicts of Interest}

The authors declare that there are no conflicts of interest regarding the publication of this paper.

\section{Acknowledgments}

This work was supported by the Key Laboratory of Agricultural information engineering of Sichuan Province and Social Science Foundation of Sichuan Province in 2019 (19GL030).

\section{References}

[1] Y. Hong, P. A. Pavlou, N. Shi, and K. Wang, "On the role of fairness and social distance in designing effective social referral systems," MIS Quarterly, vol. 41, no. 3, pp. 787-809, 2017.

[2] EMarketer, "Global ecommerce 2019 China," 2019, https:// www.emarketer.com/content/china-ecommerce-2019.

[3] Davis E., June (2009) PayPal's 2nd checkout abadonment survey results and new PayPal instant update A PI on express checkout.

[4] W.-H. Huang, G. C. Shen, and C.-L. Liang, "The effect of threshold free shipping policies on online shoppers' willingness to pay for shipping," Journal of Retailing and Consumer Services, vol. 48, pp. 105-112, 2019.

[5] Y. Jiang, J. Shang, and Y. Liu, "Optimizing shipping-fee schedules to maximize e-tailer profits," International Journal of Production Economics, vol. 146, no. 2, pp. 634-645, 2013.

[6] W.-H. Huang and Y.-C. Cheng, "Threshold free shipping policies for internet shoppers," Transportation Research Part A: Policy and Practice, vol. 82, pp. 193-203, 2015.

[7] M. Lewis, V. Singh, and S. Fay, "An empirical study of the impact of nonlinear shipping and handling fees on purchase incidence and expenditure decisions," Marketing Science, vol. 25, no. 1, pp. 51-64, 2006.

[8] ComScore, "UPS pulse of the online Shopper ${ }^{\mathrm{TM}}$ study," 2018, https://www.ups.com/assets/resources/media/pulse_online_ shopper.pdf.

[9] Z. Hua, H. Hou, and Y. Bian, "Optimal shipping strategy and return service charge under no-reason return policy in online retailing," IEEE Transactions on Systems, Man, and Cybernetics: Systems, vol. 47, no. 12, pp. 3189-3206, 2016.

[10] A. Sainathan, "Customer differentiation with shipping as an ancillary service? Free service, prioritization, and strategic delay," Decision Sciences, vol. 49, no. 4, pp. 690-727, 2018.

[11] Y. Guo, C. Yin, M. Li, X. Ren, and P. Liu, "Mobile e-commerce recommendation system based on multi-source information 
fusion for sustainable e-business," Sustainability, vol. 10, no. 2, p. 147, 2018.

[12] Y. Ma, G. Chen, and Q. Wei, "Finding users preferences from large-scale online reviews for personalized recommendation," Electronic Commerce Research, vol. 17, no. 1, pp. 3-29, 2017.

[13] S. D. Duvvuri, A. Ansari, and S. Gupta, "Consumers' price sensitivities across complementary categories," Management Science, vol. 53, no. 12, pp. 1933-1945, 2007.

[14] S.-W. Kim and P. C. Bell, "Optimal pricing and production decisions in the presence of symmetrical and asymmetrical substitution," Omega, vol. 39, no. 5, pp. 528-538, 2011.

[15] A. Ansari, S. Essegaier, and R. Kohli, "Internet recommendation systems," Journal of Marketing Research, vol. 37, no. 3, pp. 363-375, 2000.

[16] Y. Boztug and T. Reutterer, "A combined approach for segment-specific market basket analysis," European Journal of Operational Research, vol. 187, no. 1, pp. 294-312, 2008.

[17] P. Kelle, P. A. Miller, and A. Y. Akbulut, "Coordinating ordering/shipment policy for buyer and supplier: numerical and empirical analysis of influencing factors," International Journal of Production Economics, vol. 108, no. 1-2, pp. 100$110,2007$.

[18] T. Frischmann, O. Hinz, and B. Skiera, "Retailers' use of shipping cost strategies: free shipping or partitioned prices?” International Journal of Electronic Commerce, vol. 16, no. 3, pp. $65-88,2012$.

[19] R. W. Hamilton and J. Srivastava, "When $2+2$ is not the same as $1+3$ : variations in price sensitivity across components of partitioned prices," Journal of Marketing Research, vol. 45, no. 4, pp. 450-461, 2013.

[20] V. G. Morwitz, E. A. Greenleaf, and E. J. Johnson, "Divide and prosper: consumers' reactions to partitioned prices," Journal of Marketing Research, vol. 35, no. 4, pp. 453-463, 1998.

[21] B. Burman and A. Biswas, "Partitioned pricing: can we always divide and prosper?" Journal of Retailing, vol. 83, no. 4, pp. 423-436, 2007.

[22] A. Cheema, "Surcharges and seller reputation," Journal of Consumer Research, vol. 35, no. 1, pp. 167-177, 2008.

[23] M. Gümüs, S. Li, W. Oh, and S. Ray, "Shipping fees or shipping free? A tale of two price partitioning strategies in online retailing," Production and Operations Management, vol. 22, no. 4, pp. 758-776, 2013.

[24] D. J. Reibstein, "What attracts customers to online stores, and what keeps them coming back?" Journal of the Academy of Marketing Science, vol. 30, no. 4, pp. 465-473, 2002.

[25] M. Lewis, "The influence of loyalty programs and short-term promotions on customer retention," Journal of Marketing Research, vol. 41, no. 3, pp. 281-292, 2004.

[26] G. Hua, S. Wang, and T. C. E. Cheng, "Optimal pricing and order quantity for the newsvendor problem with free shipping," International Journal of Production Economics, vol. 135, no. 1, pp. 162-169, 2012.

[27] X.-F. Shao, "Free or calculated shipping: impact of delivery cost on supply chains moving to online retailing," International Journal of Production Economics, vol. 191, pp. 267-277, 2017.

[28] J. Song, Y. Yin, and Y. Huang, "A coordination mechanism for optimizing the contingent-free shipping threshold in online retailing," Electronic Commerce Research and Applications, vol. 26, pp. 73-80, 2017.

[29] Y. Jiang, J. Shang, C. F. Kemerer, and Y. Liu, "Optimizing E-tailer profits and customer savings: pricing multistage customized online bundles," Marketing Science, vol. 30, no. 4, pp. 737-752, 2011.
[30] Y. Jiang, J. Shang, Y. Liu, and J. May, "Redesigning promotion strategy for e-commerce competitiveness through pricing and recommendation," International Journal of Production Economics, vol. 167, pp. 257-270, 2015.

[31] C. Li, M. Chu, C. Zhou, and W. Xie, "Is it always advantageous to add-on item recommendation service with a contingent free shipping policy in platform retailing?" Electronic Commerce Research and Applications, vol. 37, Article ID 100883, 2019.

[32] D. Goldberg, D. Nichols, B. M. Oki, and D. Terry, "Using collaborative filtering to weave an information tapestry," Communications of the ACM, vol. 35, no. 12, pp. 61-70, 1992.

[33] B. Cai, X. W. Yang, Y. S. Huang, H. J. Li, Q. Sang, and T. Kramer, "A triangular personalized recommendation algorithm for improving diversity," Discrete Dynamics in $\mathrm{Na}$ ture and Society, vol. 2018, Article ID 3162068, p. 11, 2018.

[34] Y. Guo, M. Wang, and X. Li, "Application of an improved Apriori algorithm in a mobile e-commerce recommendation system," Industrial Management \& Data Systems, vol. 117, no. 2, pp. 287-303, 2017.

[35] A. D. J. Cooke, H. Sujan, M. Sujan, and B. A. Weitz, "Marketing the unfamiliar: the role of context and item-specific information in electronic agent recommendations," Journal of Marketing Research, vol. 39, no. 4, pp. 488-497, 2002.

[36] A. V. Bodapati, "Recommendation systems with purchase data," Journal of Marketing Research, vol. 45, no. 1, pp. 77-93, 2008.

[37] G. M. del Corso and F. Romani, "Adaptive nonnegative matrix factorization and measure comparisons for recommender systems," Applied Mathematics and Computation, vol. 354, pp. 164-179, 2019.

[38] R. Garfinkel, R. Gopal, A. Tripathi, and F. Yin, "Design of a shopbot and recommender system for bundle purchases," Decision Support Systems, vol. 42, no. 3, pp. 1974-1986, 2006.

[39] S. Yao and C. F. Mela, "Online auction demand," Marketing Science, vol. 27, no. 5, pp. 861-885, 2008.

[40] S.-y. Wu, L. M. Hitt, P.-y. Chen, and G. Anandalingam, "Customized bundle pricing for information goods: a nonlinear mixed-integer programming approach," Management Science, vol. 54, no. 3, pp. 608-622, 2008.

[41] K. Jedidi, S. Jagpal, and P. Manchanda, "Measuring heterogeneous reservation prices for product bundles," Marketing Science, vol. 22, no. 1, pp. 107-130, 2003.

[42] R. Venkatesh and W. Kamakura, "Optimal bundling and pricing under a monopoly: contrasting complements and substitutes from independently valued products," The Journal of Business, vol. 76, no. 2, pp. 211-231, 2003.

[43] Y. Chen and G. Iyer, "Research note consumer addressability and customized pricing," Marketing Science, vol. 21, no. 2, pp. 197-208, 2002.

[44] Y. Bakos and E. Brynjolfsson, "Bundling information goods: pricing, profits, and efficiency," Management Science, vol. 45, no. 12 , pp. 1613-1630, 1999.

[45] G. Aydin and S. Ziya, "Technical note-personalized dynamic pricing of limited inventories," Operations Research, vol. 57, no. 6, pp. 1523-1531, 2009.

[46] C. Kuo, H. Ahn, and G. Aydin, Dynamic Pricing of Limited Inventories when Customers Negotiate, Indiana University Bloomington, Bloomington, IN, USA, 2010. 